\title{
The Geological Study of the Role of Citizens' Participation in Improvement of Municipal Services and Environment (Case Study: Urban Area of Bagh-e Malek in Khuzestan Province of Iran)
}

\author{
Saeed Maleki ${ }^{1}$, Majid Godarzi ${ }^{1}$, Rasol Sarvestan ${ }^{2 *}$ \\ ${ }^{1}$ Department of Geography and Urban Planning, Faculty of Earth Sciences and GIS, Shahid Chamran University of Ahvaz, Ahvaz, Iran \\ ${ }^{2}$ MA Student of Geography and Urban Planning, Shahid Chamran University of Ahvaz, Ahvaz, Iran \\ Email:malekis@scu.ac.ir, saeedmale@gmail.com, ${ }^{\star}$ r.sarvestan@gmail.com
}

How to cite this paper: Maleki, S., Godarzi, M. and Sarvestan, R. (2016) The Geological Study of the Role of Citizens' Participation in Improvement of Municipal Services and Environment (Case Study: Urban Area of Bagh-e Malek in Khuzestan Province of Iran). Open Journal of Geology, 6, 1187-1195. http://dx.doi.org/10.4236/ojg.2016.69087

Received: August 18, 2016

Accepted: September 25, 2016

Published: September 28, 2016

Copyright $\odot 2016$ by authors and Scientific Research Publishing Inc. This work is licensed under the Creative Commons Attribution International License (CC BY 4.0).

http://creativecommons.org/licenses/by/4.0/

\section{(c) (i) Open Access}

\begin{abstract}
The main purpose of the present research is to study geological issues of urban areas in Bagh-e Malek in Khuzestan province of Iran and improving the municipal environment. The present research is an applied study in sake of nature and a descriptive-analytical survey in sake of method. Library and field method has been used in data collection. In field study, 325 citizens in Bagh-e Malek in 2015 were selected as sample group via sampling method well suited to sample size using questionnaire of citizens' participation. Software SPSS and Excel are used to analyze data. Friedman test has been used to determine rank of each of selected indices for testing hypotheses and finding research. Results from Friedman test indicate that satisfaction with pedestrian passages has the highest mean with rank (9.90) and awareness from municipality's rights has the lowest mean with rank (2.95).
\end{abstract}

\section{Keywords}

Geology, Environmental Geology, Participation, Municipal Services, Municipal Environment, Bagh-e Malek

\section{Introduction}

Nowadays, assignments by municipality as the most important non-profit entity have arisen by complicated structures and assignments of organizations at areas of urban management. One of assignments by municipalities is to convert inputs to outputs of 
municipal services and satisfy citizens [1]. Municipalities as the suppliers of municipal services to citizens will have successful performance when they provide comfort and security for citizens. Reaching to municipal sustainability requires understanding an analysis of existing status by means of analysis of the balance in suitable and efficient performance of these organizations ended in participation [2]. Citizens will succeed in administration of affairs and associated activities arising citizens' satisfaction; satisfaction and welfare of any society rely on creation of this feeling and attitude that citizens know themselves involved in their environmental conditions and have an active participation in fate of environment. Participation by citizen has been regarded as one of major parameters in developed cities and megacities [3]. For this, people's participation is considered as the most important factor in success of projects [4]. Nowadays we have witnessed municipal environmental problems at large extents, i.e. the factors such as traffic observance, attention to green space, collaboration with municipalities at the area of compliance with constructions, collection of waste and other problems represent the problems which we have faced them [5]. In recent years, issue of citizens' participation in administration of affairs of cities has been considered above all social and political discourses at scientific and political associations of country, so that everyone has introduced it as an important element to reach sustainable development and democracy. In the present research, an attempt is made to analyze and examine role of citizens' participation in improvement of municipal services and municipal environment at the urban areas of Bagh-e Malek, and in this way we assist the politicians and planners for citizens' participation in improvement of municipal services and municipal environment at the urban areas of Bagh-e Malek. Further, with regard to the problems arisen from defective municipal services and negative cultural and social impacts which have led to social damages across city especially in Bagh-e Malek, more attention to people's participation in municipal services and municipal environment is required, so that it can reduce these problems by people's more participation in the affairs related to their city and neighborhood. In this regard, finding a significant relationship between the variables in research hypotheses is the main purpose of study.

\section{Significant of Research}

Nowadays, the cities take step by increasing population despite development. This can be due to keeping distance from citizens' participation in municipal programs and projects so that citizens' participation at this area has faded out. Yet proportion of compatibility in management of cities relies on the linkage between cities and society in order that reality, ideas and suggestions enable to transfer to official entities [6]. Further awareness from people's needs and problems and overview of their attitude in their role to resolve municipal problems pave the way to make logical and proper linkage between the entities which provide services for citizens and raise trust among citizens and municipal management, that's why use of public participation implies resolving or reducing bottlenecks and problems in municipal management of Bagh-e Malek and on the other hand use of citizen participation causes saving energy and time. Citizens' intervention in administration of municipal environment and affairs of Bagh-e Malek has 
caused direct familiarity with problems in city, results in modification in people's view on municipal management.

\section{Literature Review}

[7] in a study entitled "civil culture, society and citizens' participation at contrasting neighborhoods" concluded that civil culture, political entities, public policies and education affect participation by citizens.

[8] conducted a paper entitled social participation and public police care and examined role of public participation at various dimensions to provide security and concluded that public police monitoring has been the most important novelty at police organization. This term ensures citizens' collaboration with police at local area, definition of the problems related to crime, determination of police priorities, detection of problem and resolving problems. Rouzbenam in a book entitled "prevention from crime" examined prevention from crime instead of treatment with offender, under which the causes for inefficiency of coercion theory of crime. Then he has examined the discussions on how the citizens' participation takes place in prevention from a variety of crimes and psychological and social discussions which can affect creation of citizens' motivation to participation. In following, he has put emphasis on role of social groups and how these groups are organized in participation in prevention from crimes. [9] examined the relationship between resident involvement in neighborhood organizations and volunteers' self-efficacy, collective efficacy, and sense of community by surveying members and participants of four neighborhood organizations in poor communities in Pittsburgh, Pennsylvania. Results demonstrated that volunteers involved in the organization's everyday activities and in decision making received the most benefits, including increased self-efficacy (leadership, policy control, neighborhood policy control, and knowledge and skills), organizational collective efficacy, and sense of community. Involvement in the everyday activities alone increased volunteers' selfefficacy and organizational collective efficacy. Implications for social work practice and strategies for developing the volunteer capacity of community-based organizations are discussed. [10] conducted a research entitled "a study on factors affecting people's participation in the affairs related to NAJA in Tehran" and examined theories on participation and causes for lack of people's participation with police in Tehran, concluded that lack of people's trust on police, failure to address the police's requests, lack of personnel's awareness from duties in treatment with people, lack of training citizens to persuade them to provide participation as the most important causes for lack of participation by people with police in Tehran.

[11] conducted a research entitled "citizens' participation in administration of municipal affairs of Isfahan" and concluded that variables of social factors have the highest effect and variables of non-material welfare and meeting cultural and early needs have the least effect on participation by citizens in municipal affairs.

[12] conducted an article entitled "barriers and challenges to management of citizens' participation in district 3 of Isfahan" and examined barriers existing in management of citizens' participation in municipal areas of district 3 of Isfahan and concluded that ef- 
fectiveness of participation, dwelling status, education, motivation and role of person in family are the inhibitors to social participation at district 3 of Isfahan.

\section{Research Method}

The applied research method has been used in this study, thus this study is a descriptiveanalytical survey. The required information in the present research has been collected via documentary, library and survey methods. The statistical population consists of citizens at Bagh-e Malek; the sample size has been determined via Cochran method. The information in questionnaire has been considered to depict diagrams using software Excel. To measure validity of questionnaire, views of advisor, supervisor and other professors have been used; to measure reliability of questionnaire, Cronbach's alpha coefficient is used. Ultimately, using Friedman test, the required tables and diagrams are prepared.

\section{Geographical Situation of Bagh-e Malek}

Bagh-e Malek is a second-order administrative division (class A-Administrative Region) in Ostan-e Khuzestan (Khuzestan), Iran (Asia) with the region font code of Russia/Central Asia. It is located at an elevation of 1039 meters above sea level. Bāgh-e Malek is also known as Bagh-e Malek, Bāgh-e Malek. Its coordinates are $31^{\circ} 30^{\prime} 0^{\prime \prime} \mathrm{N} 49^{\circ} 55^{\prime} 0^{\prime \prime} \mathrm{E}$ in DMS (Degrees Minutes Seconds) or 31.5 and 49.9167 (in decimal degrees). Its UTM position is UQ98 and its Joint Operation Graphics reference is NH39-02. Current local time is 12:35; the sun rises at 07:56 and sets at 20:03 local time (Asia/Tehran UTC/GMT + 4.5). The standard time zone for Bagh-e Malek is UTC/GMT +3.5 , but since Daylight Saving Time (DST) is in effect the current time zone is UTC/GMT + 4.5.

\section{Reliability and Validity of Questionnaire of Citizens' Participation Measurement}

To measure reliability of questionnaire, Cronbach's alpha is the most suitable method regarding use of 5-point Likret scale. This method is made using software SPSS shown the results in Table 1. The results from Cronbach's alpha have been calculated. Thus on the whole validity and reliability of the questionnaire have been at suitable level and found trustful for field study.

\section{Data Analysis of This Research}

In this section, firstly dependent and independent variables are expressed for each hypothesis and then Friedman test has been used to understand relationship or lack of relationship between two variables so as to rank the data from citizens' participation, satisfaction with municipal services and awareness from citizens.

Table 1. Number of variables and value of Cronbach's alpha.

\begin{tabular}{cc}
\hline Number of variables & Cronbach's alpha \\
\hline 40 & 0.875 \\
\hline
\end{tabular}




\section{Analysis of Friedman Test}

In this section, each of variables of citizens' participation in improvement of municipal services and municipal environment has been ranked via Friedman test.

Findings relating to citizen participation:

With regard to the existing data which depend on comparison of mean of ranks of 15 groups of data, Friedman test has been used. A summary of results from this analysis has been reported in Table 2. In this table, freedom degree and sig, sig of scores, mean of ranks of scores of sample, chi-square have been reported.

As known, if sig be under standard error, sig is proven at that level. As shown, the obtained chi-square (79.37) is significant at $\mathrm{p}<000$. To observe differences at these areas of people participation, diagram has been depicted and reported (Figure 1).

With regard to the existing data which depend on comparison of mean of ranks of 15 groups of data, Friedman test has been used. A summary of results from this analysis

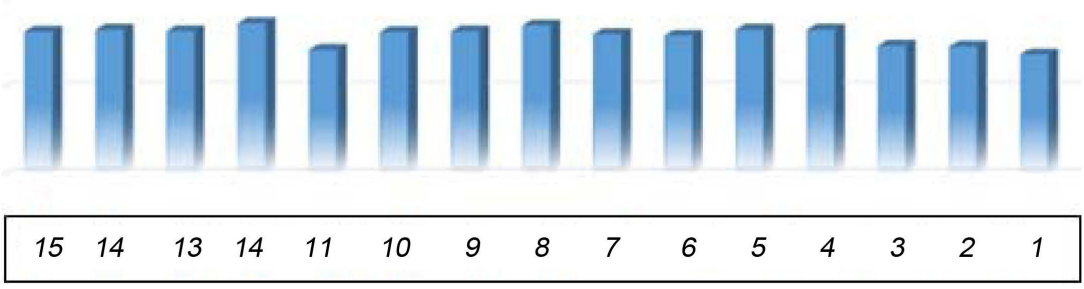

Figure 1. Friedman test to compare ranks in citizens' participation findings relating to municipal services.

Table 2. Friedman test to compare ranks in citizens' participation.

\begin{tabular}{|c|c|c|c|c|c|}
\hline Row & Variables & Sample siz & Mean & an of rank & $\mathrm{X}^{2} \mathrm{df}$ sig \\
\hline 1 & Participation in associations and ceremonies & 325 & 2.90 & 6.91 & \\
\hline 2 & Participation in maintaining green urban space & 325 & 2.99 & 7.36 & \\
\hline 3 & Participation in respect for rules and rights & 325 & 2.97 & 7.41 & \\
\hline 4 & Evaluation of the extent to which services have been provided by municipal managers & 325 & 3.20 & 8.32 & \\
\hline 5 & Participation in paying taxes & 325 & 3.18 & 8.32 & \\
\hline 6 & Participation in providing better services & 325 & 3.11 & 7.99 & \\
\hline 7 & Participation in notification & 325 & 3.10 & 8.08 & \\
\hline 8 & Participation in municipality and related directors & 325 & 3.25 & 8.57 & 79.3714000 \\
\hline 9 & Participation in resolving municipal problems & 325 & 3.30 & 8.23 & \\
\hline 10 & Participation in local decisions & 325 & 3.16 & 8.20 & \\
\hline 11 & Participation in collection of wastes & 325 & 2.95 & 7.17 & \\
\hline 12 & Study catalogs & 325 & 3.26 & 8.70 & \\
\hline 13 & Attention to rules in constructions & 325 & 3.15 & 8.24 & \\
\hline 14 & Propose suggestions to municipal directors & 325 & 3.20 & 8.32 & \\
\hline 15 & Participation in pooling & 325 & 3.24 & 8.22 & \\
\hline
\end{tabular}


has been reported in Table $3 \&$ Table 4.

To observe differences at these thirteen areas of municipal services, the diagram has been depicted and reported in Figure 2.

Findings relating to citizens' awareness:

Table 3. Friedman test to compare ranks in citizens' satisfaction with municipal services in Bagh-e Malek.

\begin{tabular}{|c|c|c|c|c|c|}
\hline Row & Variables & Sample size & Mean & Mean of rank & df sig \\
\hline 1 & Satisfaction with municipal services & 325 & 3.60 & 7.58 & \\
\hline 2 & Satisfaction with municipality's notification & 325 & 3.60 & 7.39 & \\
\hline 3 & Satisfaction with collection of wastes & 325 & 3.48 & 6.34 & \\
\hline 4 & Satisfaction with health services & 325 & 3.86 & 6.92 & \\
\hline 5 & Satisfaction with sports clubs & 325 & 3.58 & 7.39 & \\
\hline 6 & Satisfaction with staffs' treatment & 325 & 3.56 & 7.30 & \\
\hline 7 & Satisfaction with ceremonies and conferences & 325 & 3.36 & 6.54 & 720.4512000 \\
\hline 8 & Satisfaction with recreational services & 325 & 3.36 & 6.54 & \\
\hline 9 & Satisfaction with educational services & 325 & 3.28 & 6.26 & \\
\hline 10 & Satisfaction with projecting at night & 325 & 3.65 & 4.24 & \\
\hline 11 & Satisfaction with green space and environment & 325 & 2.89 & 5.06 & \\
\hline 12 & Satisfaction with pedestrian passages & 325 & 4.31 & 9.90 & \\
\hline 13 & Satisfaction with children parks & 325 & 4.23 & 9.52 & \\
\hline
\end{tabular}

Table 4. Friedman test to compare ranks in citizens' awareness at Bagh-e Malek.

\begin{tabular}{cccccc}
\hline row & Variables & Sample size & Mean & Mean of rank & $\mathrm{X}^{2}$ df \\
\hline 1 & Awareness from our duties against municipality & 325 & 2.88 & 3.02 & \\
2 & Awareness from out rights against municipality & 325 & 2.88 & 3.07 & \\
3 & Awareness from municipality's duties & 325 & 2.82 & 2.95 & 8.97540 .620 \\
4 & Awareness form municipality's rights & 325 & 2.93 & 3.12 & \\
5 & Awareness from rules and regulations & 325 & 2.76 & 2.84 & \\
\hline
\end{tabular}

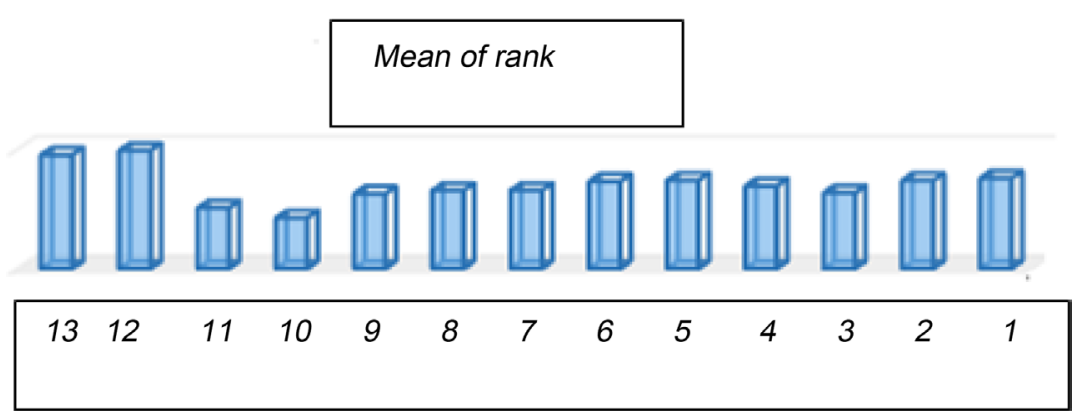

Figure 2. Friedman test to compare ranks at satisfaction with municipal services at Bagh-e Malek. 
With regard to the obtained information, mean of given scores by sample group is different in five parts of Awareness from our duties against municipality, awareness from our rights against municipality, awareness from municipality's assignments, awareness from rights of municipality, awareness from rules and regulations of municipality. To observe differences at this area, their diagram has been depicted and reported (Figure 2).

Citizens' participation in improvement of municipal services and municipal environment is significant and at suitable status, indicating suitable performance of municipality at this region and high awareness of citizens, that is, citizens' participation in improvement of municipal services and municipal environment increases by increasing citizens' awareness (Figure 3).

\section{Conclusion}

Nowadays, the cities take step by increasing population despite development. This can be due to keeping distance from citizens' participation in municipal programs and projects so that citizens' participation at this area has faded out [13]. With regard to the findings from citizens' participation, scores given to the sample group to fifteen parts of participation in participation in associations and ceremonies, participation in maintaining green urban space, participation in respect for rules and rights, evaluation of the extent to which services have been provided by municipal managers, participation in paying taxes, participation in providing better services, participation in notification, participation in municipality and related directors, participation in resolving municipal problems, participation in local decisions, participation in collection of wastes, study catalogs, attention to rules in constructions, proposed suggestions to municipal directors, and participation in pooling are different. With regard to obtained findings, it can conclude that people's participation with municipality and affiliated directors is greater than rest of activities in Bagh-e Malek and participation in conference and ceremonies is given less percent [14] [15]. In this regard, it can say that municipal management of Bagh-e Malek for citizens' participation has not outperformed. With regard to the findings from satisfaction with municipal services, scores given to the sample group to thirteen parts including satisfaction with municipal services, satisfaction with municipality's notification, satisfaction with collection of wastes, satisfaction with health services, satisfaction with sports clubs, satisfaction with staffs' treatment, satisfaction with

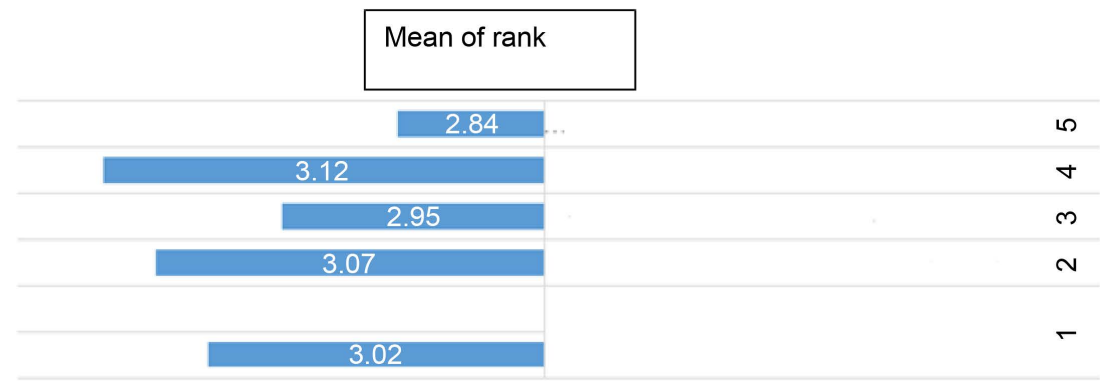

Figure 3. Friedman test to compare ranks in citizens' awareness at Bagh-e Malek. 
ceremonies and conferences, satisfaction with recreational services, satisfaction with educational services, satisfaction with projecting at night, satisfaction with green space and environment, satisfaction with pedestrian passages and satisfaction with children parks are different. With regard to these findings, it can conclude that the most effective factor in municipal services is satisfaction with pedestrian passages and the least effective barrier to municipal services is projecting at night, found as the cause for proving effect of urban management in administration of city. As shown variables of satisfaction with Children Park, satisfaction with municipal transport, satisfaction with municipality's notification, satisfaction with sports areas, and satisfaction with staffs' treatment are at next stage. In this regard, it can say that municipal services are different from point of view of citizens, not found with the same importance. With regard to findings relating to citizens' awareness, it can conclude that municipal managers have not agreed on notifying people. According to the citizens in Bagh-e Malek, awareness from municipality's rights has outperformed rest of variables and awareness from rules and regulations of municipality has been given the least priority than municipal managers of Bagh-e Malek. As observed, awareness from our rights against municipality has outperformed than awareness from municipality's assignments. Among all the indices of citizens' participation in municipal services and municipal environment, satisfaction with pedestrian passages has the highest mean with rank 9.90 and the awareness from municipality's rights has the least mean with rank 2.95.

\section{References}

[1] Ansari, H. (2006) Factors Influencing People's Participation in Affairs Relating to Police in the City of Tehran. Collection. Conference of Social Security, No. 26, 141.

[2] Skoog, W.J. (2004) Social Participation and Disciplinary Care for Everyone. Translated by Dr. A. Masoudnia, Second and Third Studies, Social Security Number, 183.

[3] Rajabi, A. (2011) Methods of Citizen Participation in Urban Development Processes. Geographical Journal of Environmental Planning, 101, 116.

[4] Abbas Zadeh, M. (2008) Factors Affecting the Participation of Citizens in the City (Case Study: Isfahan). Sociology Doctoral Dissertation, University of Isfahan.

[5] Firuzi, M. (2006) Right of Participation to the Environment, the SID, and the Secretariat of Student Thesis, Tehran, Statistical Center of Iran, Khuzestan General Population and Housing Census 1385, 62-64.

[6] Monazami Tabar, J. (2006) The Role of Public Participation in Strengthening Social Security. Police Knowledge, No. 1.

[7] Momeni, M. (2006) New Topics Operations Research, Management Tehran University Press.

[8] Consulting Engineers of Arman Shahr (1998) Developing Ways of Improving the Efficiency of Urban Services.

[9] Nouri, R. (2013) Factors Influencing Citizen Participation in Urban Management, Urban Distressed Areas (Case Study of Baghmalek). Master's Thesis, Shahid Chamran University Department of Geography and Urban Planning.

[10] Chakrabarty, B.K. (2001) Urban Management, Concepts, Principles, Techniques and Education. Cities, 18, 331-345. http://dx.doi.org/10.1016/S0264-2751(01)00026-9 
[11] Harvey, D. (2009) Social Justice and the City. The University of Georgia Press, Athens, Revised Edition.

[12] Sanoff, H. (2000) Community Participation Methods in Design and Planning. John Wiley \& Sons, New York.

[13] Marschall, M.J. (2004) Citizen Participation and the Neighborhood Context: A New Look at the Coproduction of Local Public Goods. Political Research Quarterly, 57, 231-244. http://dx.doi.org/10.1177/106591290405700205

[14] Docherty, I., Goodlad, R. and Paddison, R. (2001) Civic Culture Community and Citizen Participation in Contrasting Neighbourhoods. Urban Studies, 38, 2225-2250. http://dx.doi.org/10.1080/00420980120087144

[15] Ohmer, M.L. (2007) Citizen Participation in Neighbourhoods Organizations in Poor.

\section{Submit or recommend next manuscript to SCIRP and we will provide best service} for you:

Accepting pre-submission inquiries through Email, Facebook, LinkedIn, Twitter, etc. A wide selection of journals (inclusive of 9 subjects, more than 200 journals)

Providing 24-hour high-quality service

User-friendly online submission system

Fair and swift peer-review system

Efficient typesetting and proofreading procedure

Display of the result of downloads and visits, as well as the number of cited articles

Maximum dissemination of your research work

Submit your manuscript at: http://papersubmission.scirp.org/

Or contact ojg@scirp.org 